\title{
METHODS FOR DESCRIBING THE SHAPE OF DEFECTIVE NANOSTRUCTURED FORMATIONS IN MATERIALS UNDER IRRADIATION
}

\author{
A.I.Kul'ment'ev* \\ Institute of Applied Physics of NASU, st. Petropavlovskaya, 58, 40030, Sumy, Ukraine
}

(Received June 20, 2018)

\begin{abstract}
Within the framework of the program of using modern computer methods in the task of developing radiation-resistant materials for IV-generation reactors, several methods for describing the form of local atomic segregations or compact radiation defects of the nanometer range have been considered. A numerical method for measuring the shape of an arbitrary atomic formation possessing a well-defined external boundary is proposed. The shape of the sequence of equilibrium clusters is measured, the interaction of the particles in which is described by the Lennard-Jones potential. It is shown that the proposed method correctly reproduces the oscillations of size effects and the sequence of magic numbers for these clusters. The possibility of replacing geometric moments by the moments of Zernike $3 D$ functions is considered. Such a replacement allows us to get rid of the ill-posed nature of the inverse problem in the transition from the source space of clusters form to the space of their descriptors.
\end{abstract}

PACS: 61.72.Qq

\section{INTRODUCTION}

In the active zone of the fission reactor, structural materials are exposed to ionizing particle fluxes during the entire operation time. This leads to changes of the structure and properties of materials in wide space-time scales. Of particular importance here are complex defects with characteristic dimensions of $10 \ldots 1000 \mathrm{~nm}$, which 1) are the result of the natural evolution of primary radiation defects; 2) can have sufficiently long lifetimes; 3) often have a complex spatial structure. Such defects in many cases determine the properties of materials that are critical in deciding the possibility to use the material under consideration in such an aggressive environment as the active zone of fission reactors (existing and projected).

Indeed, it is well known, that defects generated by radiation damage include vacancies, self-interstitial atoms, gas atoms and clusters of these defects. As these defects accumulate and interact within a metal, they can agglomerate into larger defect clusters [1]. Depending on the constituents of a given cluster and the type of metal lattice, clusters can take a variety of geometric forms.

The majority of commercial nuclear reactors in the world today are light water reactors. The nuclear fuel used in these reactors is in the form of fuel rods, which consist of long tubes (approximately $4 \mathrm{~m}$ long, with approximately $1 \mathrm{~cm}$ diameter and $0.6 \mathrm{~mm}$ wall thickness) made out of zirconium alloys and which contain uranium dioxide pellets. These tubes (so called nuclear fuel cladding) constitute the first barrier against the release of fission products into the primary circuit. Because of this important function, it is crucial to nuclear safety to ensure cladding integrity during service.

The detailed study of oxide layer microstructure has yielded considerable insights onto atomic level into growth mechanism of oxide layers in zirconium alloys exposed to high-temperature water. For alloys that form a protective oxide layer in this conditions, the oxide growth is stable, the oxide is adherent, and no evidence of meaningful dissolution of the outer oxide is seen.

Microstructure examination shows that oxidation starts by the formation of small, equiaxed oxide grains on the metal near the oxide/water interface [2]. These small oxide grains are more or less randomly oriented and exhibit a mix of tetragonal and monoclinic $\mathrm{ZrO}_{2}$ crystal structures. As the grains grow, they become columnar so as to favor the growth of properly oriented grains to minimize the stress accumulation.

The transition from equiaxed to columnar growth occurs at a diameter of approximately $30 . .40 \mathrm{~nm}$. The columnar grains grow to a length of approximately $200 \mathrm{~nm}$, at which point grains normally have to renucleate to maintain the proper orientation. This anisotropic columnar growth results in a fiber texture with long, columnar oxide grains formed in between transitions and small, equiaxed grains formed at the beginning of the corrosion process and at the oxide transition.

\footnotetext{
*Corresponding author E-mail address: kulmentev@ukr.net; tel.: (380-542) 60-58-67
} 
As the oxide grows, stresses accumulate in the oxide layer from the imperfect accommodation of the volume expansion associated with oxidation. Inplane stresses on the order of $1 \ldots 3 G P a$ have been measured in growing oxide films at various stages of film growth [3]. In parallel, oxide porosity develops in the layer [4]. This porosity takes the form of small tubes near or at the columnar oxide grain boundaries.

The pores first start out as equiaxed cavities and grow into tubes as the oxide grows, as has been shown by transmission electron microscopy [5]. The increasing stress eventually causes lateral cracks to form, which causes an interlinkage of the porosity from the oxide/metal to the oxide/water interface, thus providing easy access to the water, which in turn increases the corrosion rate. The sudden nature of the transition is then related to the sudden oxide breakup after the stress reaches a critical value. The interlinkage of pores explains how lateral cracks can cause an overall loss of protectiveness. This is thought to be the mechanism related to the oxide transition [6].

The pore system developed in the oxide film has a complex shape, and therefore it is desirable to have a computational tool that allows for a quantitative description of such a characteristic. The constantly increasing power of modern computing devices makes it quite realistic in the near future to formulate the problem of computer modeling of the growth mechanism of oxide layers at the atomic level. It is clear that in addition to high computer productivity, an algorithm is needed to solve such a problem, which 1) would detect the appearance on the atomic level of a compact formation of nanometer sizes with a well-defined surface (for example, pores) and 2) provide the possibility of calculating its arbitrary integral characteristic.

In the paper, we propose methods for solving both of these problems. In accordance with this, Section 2 describes the developed numerical method for identifying the surface of a compact nanoobject. This method is simple enough, effective, stable, and allows for a clear geometric interpretation.

The proposed method provides simultaneous unambiguous determination of surface atoms and mosaic representation of the latter, which can then be used to calculate various integral characteristics. In Section 3, a method for calculating the shape of a compact cluster is developed. In the framework of the approach based on geometric moments, analytical expressions for the components of the shape vector were obtained for the first time.

Using the example of self-sustaining atomic clusters, it was shown that the proposed method correctly reproduces dimensional oscillations and a sequence of magic numbers. In conclusion (Section 4) it is proposed to replace the geometric moments with the moments of the $3 D$ Zernike functions. In our opinion, this makes possible to get rid of the ill-posed nature of the inverse problem in the transition from the source space of clusters form to the space of their descriptors.

\section{METHOD OF SURFACE DESCRIPTION OF COMPACT NANOOBJECT}

In the problem of describing the surface of a compact nanoobject, two components can be distinguished. First, an algorithm is needed that could determine whether a given atom is part of the surface or not. And, secondly, it is necessary to ensure the identification of the surface as a whole as a single connected entity.

The problem of separating surface atoms is a classification problem, which, in accordance with the accepted criterion, allows us to separate all atoms of the system into two nonoverlapping sets: those lying and not lying on the surface. There are many such criterion of physical or geometric nature. In the paper approach based on the concept of rolling on the surface of the probe sphere was used.

In accordance with this, a smooth surface $\partial \Omega$ bounding some closed domain $\Omega$, and a probe sphere of radius $R_{s}$ were considered. For an arbitrary position of the center of the sphere, the intersection of its surface and the domain $\Omega$ can be empty, containing one point or a continuum of points. In the first case, the sphere lies entirely outside the domain $\Omega$, in the second case it touches the surface $\partial \Omega$ at a single point, and in the third - contains the interior points of the domain $\Omega$. Hence it follows that the surface can be represented as a union of one-point sets corresponding to all possible positions of the probe sphere rolling on the surface.

If we consider the collection of subsets $S_{i}$ of the positions of the probe sphere in which it touches simultaneously $i$ atoms of the surface, then it can be shown that $S_{1}$ and $S_{2}$ have the cardinality of the continuum, and the set $S_{3}$ is finite. This circumstance was used to discretize the surface of a compact nanoobject.

For this purpose, a fixed position of the probe sphere was determined as such, in which it is in simultaneous contact with three atoms and does not overlap with any other atom (Fig.1,a). Clearly, from a dynamic point of view, in this case the sphere can not roll further without loss of contact, at least with one of the atoms. The centers of these atoms form the vertices of a triangle - an element of the so-called $r$-reduced surface - and in the method under consideration the surface of a compact atomic formation is defined as an $r$-reduced surface.

If the first element of the surface is given, then the next element can be determined by rolling the probe sphere through any of its edges (sides of the triangle) so that it maintains contact with two atoms of three (in Fig.1,b - with atoms A and B) until the sphere does not touch the third atom of the next surface element. It is important that any of the edges of the $r$-reduced surface is a common edge of two adjacent triangular elements.

Therefore, the partial nature of the system under 


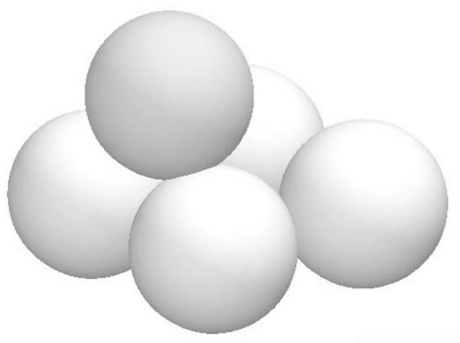

a

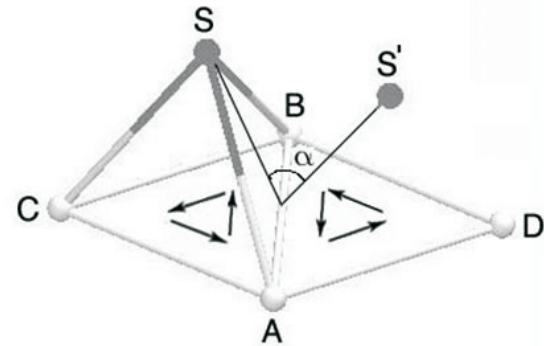

b

Fig.1. The fixed position of the probe sphere (darkened) with the center at the point $S$, at which it simultaneously touches three atoms $A, B$ and $C$ of the surface (a); an illustration of the transition from the given to the next fixed position of the sphere (b)

consideration leads to a natural discretization of the $r$-reduced surface, and the successive rolling of the probe sphere through the unexplored edges ensures the bonding of all triangular elements of the surface into a single whole.

\section{BASED ON GEOMETRIC MOMENTS METHOD OF MEASUREMENT FORM OF THE ATOMIC CLUSTER}

One of the mandatory characteristics of an atomic cluster is its shape. According to the definition [7], "the shape of an object is that geometric information that remains after separation from the object of everything that is associated with possible changes in its scale, movements and rotations in space."
There are widespread use of methods in which representation of forms is based on global features of the object, for example, geometric moments. For an arbitrary object bounded by a closed surface, its moments are defined as follows

$$
m_{p, q, r}=\iiint x^{p} y^{q} z^{r} D(\vec{r}) d^{3} r,
$$

where $D(\vec{r})$ is the indicator function of the object, integration is carried out over the whole space, $(p, q, r)$ - a triplet of nonnegative integers, and $p+q+r$ - is the order of the moment. The moments of the lowest orders include the volume of the object $V=m_{000}$ and three moments of the first order $m_{100}, m_{010}, m_{001}$, which allow us to calculate the coordinates of its center of mass:

$$
\bar{x}=\frac{m_{100}}{m_{000}}, \quad \bar{y}=\frac{m_{010}}{m_{000}}, \quad \bar{z}=\frac{m_{001}}{m_{000}} .
$$

The set of all moments (1) uniquely determines the indicator function. A partial, albeit fairly accurate, description of the shape of the object can be obtained on the basis of a finite subset of the moments $\left\{m_{p, q, r}\right\}$, from which it is necessary to form the components of the characteristic vector. It is necessary that each component of the vector must be invariant with respect to the movement of the object, a change of its scale or rotation as a whole in space. In order to satisfy the first condition, it is sufficiently to replace the moments (1) by the central moments

$$
M_{p, q, r}=\iiint(x-\bar{x})^{p}(y-\bar{y})^{q}(z-\bar{z})^{r} D(\vec{r}) d^{3} r .
$$

Equally simple the scale invariance may be achieved - as a result of isometric scaling of central moments. The first systems approach to achieving the invariance of the components of the characteristic vector with respect to rotations was proposed in 1989 [8] and was based on group theory and tensor analysis. In [9], a method was proposed for describing the form, in which only second-order moments and their invariants are used:

$$
\begin{aligned}
& O_{1}=M_{200}+M_{020}+M_{002} \\
& O_{2}=M_{200} M_{020}+M_{200} M_{002}+M_{020} M_{002}-M_{110}^{2}-M_{101}^{2}-M_{011}^{2} \text {, } \\
& O_{3}=M_{200} M_{020} M_{002}+2 M_{110} M_{101} M_{011}-M_{200} M_{011}^{2}-M_{020} M_{101}^{2}-M_{002} M_{110}^{2} \text {. }
\end{aligned}
$$

To achieve scale invariance, the components $O_{1}$, $\mathrm{O}_{2}$ and $\mathrm{O}_{3}$ should be divided by $V$ to an appropriate degree. Therefore, in [9], the characteristic descriptor with three components was used as the shape descriptor:

$$
\Omega_{1}=\frac{3 V^{5 / 3}}{O_{1}}, \quad \Omega_{2}=\frac{3 V^{10 / 3}}{O_{2}}, \quad \Omega_{3}=\frac{V^{5}}{O_{3}} .
$$

Exact expressions for components (5) are obtained for a number of three-dimensional objects (tetrahe- dron, cube, octahedron, ellipsoid, sphere, etc.) and are shown that the maximum value $\left(\Omega_{1}^{S}, \Omega_{2}^{S}, \Omega_{3}^{S}\right)$ is realized for the sphere. Therefore, the last step consists of introducing the normalized components

$$
\bar{\Omega}_{1}=\frac{\Omega_{1}}{\Omega_{1}^{S}}, \quad \bar{\Omega}_{2}=\frac{\Omega_{2}}{\Omega_{2}^{S}}, \quad \bar{\Omega}_{3}=\frac{\Omega_{3}}{\Omega_{3}^{S}},
$$

which vary from 0 to 1 . 
Thus, in the proposed approach, the shape of the compact atomic formation is described by the characteristic vector $\left(\bar{\Omega}_{1}, \bar{\Omega}_{2}, \bar{\Omega}_{3}\right)(6)$, and the measurement of the particular components of this vector is based on the calculation of the three-dimensional integrals (1) and (3). A special form of the integration domain i.e. the polyhedron bounded by an $r$-reduced surface and the type of the integrand allowed obtain an effective scheme for calculating the exact values of the geometric moments.

This scheme is based on the Ostrogradsky-Gauss theorem, according to which the calculation of the volume integral of some scalar field $f(\vec{r})$ reduces to the calculation of the flux through the boundary of this volume of the vector field $\vec{F}(\vec{r})$, such that $\operatorname{div} \vec{F}(\vec{r})=f(\vec{r})$. In the previous author's work [10] an explicit expression for the field $\vec{F}(\vec{r})$ was obtained in the case $f(\vec{r})=x^{p_{1}} y^{p_{2}} z^{p_{3}}$ :

$$
\vec{F}(\vec{r})=\frac{x^{p_{1}} y^{p_{2}} z^{p_{3}}}{3}\left(\frac{x}{p_{1}+1}, \frac{y}{p_{2}+1}, \frac{z}{p_{3}+1}\right) .
$$

The flow of $\vec{F}(\vec{r})$ through the boundary of the polyhedron $\Sigma$ is equal to the sum of the flows through individual polygons, i.e.

$$
\int_{\Sigma} \vec{F}(\vec{r}) \cdot \vec{n} d s=\sum_{i=1}^{N} \int_{\Delta A_{i} B_{i} C_{i}} \vec{F}(\vec{r}) \cdot \vec{n}_{i} d s
$$

The transition to natural coordinates and the use of the Newton binomial formula make it possible to obtain an exact expression for the contribution at moment (1) from the flow $\vec{F}(\vec{r})$ through the polygon with vertices at the points $A=\left(x_{1}, y_{1}, z_{1}\right)$, $B=\left(x_{2}, y_{2}, z_{2}\right)$, and $C=\left(x_{3}, y_{3}, z_{3}\right):$

$$
\begin{array}{r}
m_{p_{1}, p_{2}, p_{3}}=\int_{\triangle A B C} \frac{x^{p_{1}} y^{p_{2}} z^{p_{3}}}{3}\left(\frac{x n_{x}}{p_{1}+1}+\frac{y n_{y}}{p_{2}+1}+\frac{z n_{z}}{p_{3}+1}\right) d s= \\
=\frac{2 S}{3(P+3) !} \sum_{k_{1}=0}^{p_{1}} \sum_{k_{2}=0}^{p_{2}} \sum_{k_{3}=0}^{p_{3}}\left(\begin{array}{c}
p_{1} \\
k_{1}
\end{array}\right)\left(\begin{array}{c}
p_{2} \\
k_{2}
\end{array}\right)\left(\begin{array}{c}
p_{3} \\
k_{3}
\end{array}\right) x_{3}^{p_{1}-k_{1}} y_{3}^{p_{2}-k_{2}} z_{3}^{p_{3}-k_{3}}(P-K) ! \times \\
\times \sum_{j_{1}=0}^{k_{1}} \sum_{j_{2}=0}^{k_{2}} \sum_{j_{3}=0}^{k_{3}}\left(\begin{array}{c}
k_{1} \\
j_{1}
\end{array}\right)\left(\begin{array}{c}
k_{2} \\
j_{2}
\end{array}\right)\left(\begin{array}{c}
k_{3} \\
j_{3}
\end{array}\right) x_{1}^{j_{1}} y_{1}^{j_{2}} z_{1}^{j_{3}} x_{2}^{k_{1}-j_{1}} y_{2}^{k_{2}-j_{2}} z_{2}^{k_{3}-j_{3}}(K-J) ! \times \\
\times\left[\varphi_{1}+\varphi_{2}+\varphi_{3}+\left(\varphi_{1}-\varphi_{2}\right) J+\left(\varphi_{2}-\varphi_{3}\right) K+\varphi_{3} P\right], \\
P=\sum_{i=1}^{3} p_{i}, \quad J=\frac{n_{x} x_{i}}{p_{1}+1}+\frac{n_{y} y_{i}}{p_{2}+1}+\frac{n_{z}}{p_{3}+1}, \\
\sum_{i=1}^{3} j_{i}, \quad K=\sum_{i=1}^{3} k_{i} .
\end{array}
$$

The developed method was used to measure the shape of equilibrium atomic clusters, the interparticle interaction in which is given by the LJpotential. At zero temperature, the equilibrium atomic configuration corresponds to the minimum of the potential energy, which for a cluster containing $n$ atoms is a function in $3 n$-dimensional space:

$$
U\left(\vec{r}_{1}, \vec{r}_{2}, \ldots, \vec{r}_{n}\right)=\sum_{i=1}^{n} \sum_{j=i+1}^{n} V\left(r_{i j}\right)=4 \varepsilon \sum_{i=1}^{n} \sum_{j=i+1}^{n}\left[\left(\frac{\sigma}{r_{i j}}\right)^{12}-\left(\frac{\sigma}{r_{i j}}\right)^{6}\right]
$$

Here $r_{i j}=\left|\vec{r}_{i}-\vec{r}_{j}\right|$ is the distance between atoms $i$ and $j$.

Atomic clusters are one of the most actively studied objects of nanophysics. They are characterized by the existence of oscillating dimensional effects. The latter are due to the fact that small atomic systems often have a pronounced shell structure, and the local extremum of properties corresponds to the filling of the current shell. In particular, for LJ-clusters, 
as the number of atoms increases, the icosahedral shells are formed and filled, each of which consists of 20 regular triangles. These shells correspond to the following sequence of magic numbers:

$$
n=\frac{10}{3} z^{3}+5 z^{2}+\frac{11}{3} z+1,
$$

where the integer $z$ is the order of the shell. For $z=1,2,3,4$ it follows from (14) that $n=13,55,147,309$, respectively.

It should be noted that at present none of the optimization methods can be used to ensure a global minimum of the potential energy of an atomic cluster, the number of particles in which exceeds several dozen. Nevertheless, the application of all methods allowed to determine such minima for the set of LJclusters. Data on their atomic structure are collected in an open international database [11].

The developed method was used to measure the shape of clusters with $4 \leq n \leq 150$. At the first step, the atoms of the outer surface of the cluster were determined and the corresponding polyhedron was formed, and on the second step the components of the characteristic shape vector were measured.

The obtained dependences $\bar{\Omega}_{1}(n), \bar{\Omega}_{2}(n)$ and $\bar{\Omega}_{3}(n)$, are shown in Fig.2. It can be seen from the figure that as the number of particles in the LJ-cluster increases, its shape approaches the shape of the sphere, but the convergence is nonmonotonic. From general considerations, it can be expected that filling the next shell of the cluster should lead to the formation of atomic formation - a magic cluster - with a high spherical symmetry. On the dependencies $\bar{\Omega}_{1}(n), \bar{\Omega}_{2}(n), \bar{\Omega}_{3}(n)$, this should be manifested in the form of local maxima for all values simultaneously. It is seen from Fig.2 that really for $n=13$ and $n=55$ there are pronounced local maxima which correspond to the filling of the first and second icosahedral shells respectively.

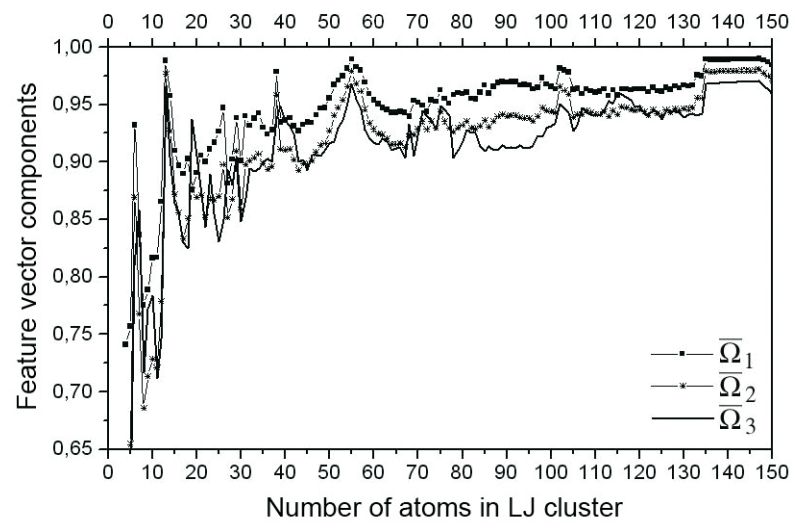

Fig.2. Dependences of the components of the characteristic vector of the shape of equilibrium $L J$-clusters on the number of particles

\section{SUMMARY AND CONCLUSIONS}

The method described above, based on geometric moments (1), can be considered as a special case of a general approach. In the context of shape analysis moments are defined as projections of the indicator function, $D(\vec{r})$ onto a set of functions $\Psi=\left\{\Psi_{i}\right\}$; $i \in \aleph$. $D(\vec{r})$, also known as the characteristic function or shape function, is a stepwise function equal to 1 inside the object and 0 outside. The general moments of this function with respect to a set of polynomial basis functions, $P_{p q r}(\vec{r})$, are defined as

$$
\mu_{p, q, r} \equiv \iiint d^{3} r D(\vec{r}) P_{p, q, r}(\vec{r})=\left\langle D, P_{p, q, r}\right\rangle
$$

where $\langle f, \Psi\rangle$ is a dot product on the Hilbert space of finite energy functions $f, \Psi \in L^{2}$.

The simplest $3 D$ moment basis functions are the Cartesian functions $P_{p, q, r}(\vec{r})=x^{p} y^{q} z^{r}$, from which the geometric moments $m_{p, q, r}(1)$ are derived. The behavior and properties of a particular moment based representation are determined by the set of functions $\Psi$. The desirable properties of a descriptor based on moments can be summarized as follows:

1) Invariance. If $F(f)$ is a set of descriptors computed on the indicator function $D(\vec{r})$, and let $G$ be a group of transformations. The invariance of $F$ under the action of $G$ means that $F(g f)=F(f)$, where $g \in G$. A typical requirement is the invariance under the action of similarity transformations, i.e. uniform scaling, reflection, translation and rotation.

2) Orthonormality. The collection of functions $\Psi$ is orthonormal, if $\left\langle\Psi_{i}, \Psi_{j}\right\rangle=\delta_{i j}$.

3) Completeness. The set of functions $\Psi$ forms a complete system if

$$
\lim _{n \rightarrow \infty}\left\|D(\vec{r})-\sum_{i=0}^{\infty}\left\langle D(\vec{r}), \Psi_{i}\right\rangle \Psi_{i}\right\|^{2}=0,
$$

where $\|\ldots\|$ denotes the $L^{2}$-norm.

The orthogonality of function collection $\Psi$, i.e. the mutual independence of computed features is an important property, since it implies that a set of features will not contain redundant information. The non-orthogonality (as in the case of geometrical moments based on monomials) means that some characteristics of the objects will be overrepresented. The completeness property implies that it is possible to reconstruct approximations of the original object from moments. The approximations are getting finer with increasing number of moments and converge to the original object at infinity. This is of considerable practical importance.

In these respect selection $\Psi$ as $3 D$ Zernike functions are preferable than Cartesian functions because the former are orthogonal over the unit ball and allow for an arbitrary shape, scaled to fit inside an embedding sphere, to be decomposed into $3 D$ harmonics. $3 D$ Zernike functions were introduced by Canterakis [12]. It should be stressed that moments of $3 D$ Zernike functions may be expressed through geometrical moments (1). Therefore developed in this paper analytical forms for the latter in the case of compact radiation nanodefects allows us to develop fast com- 
putational scheme for quantitative description form of these defects.

\section{References}

1. S.J.Zinkle, B.N. Singh. Microstructure of neutronirradiated iron before and after tensile deformation // Journal of Nuclear Materials. 2006, v.351, N1, p.269-284.

2. B.D. Gabory, A.T. Motta. Structure of Zircaloy 4 oxides formed during autoclave corrosion // Light Water Reactor Fuel Performance Meeting (Top Fuel 2013), Pap. 8584. La Grange Park, IL: ANS.

3. E. Polatidis, P. Frankel, J. Wei, M. Klaus, R.J. Comstock, et al. Residual stresses and tetragonal phase fraction characterisation of corrosion tested Zircaloy-4 using energy dispersive synchrotron X-ray diffraction // J. Nucl. Mater. 2013, v.432, p.102-112.

4. N. Ni, S. Lozano-Perez, M.L. Jenkins, C. English, G.D.W.Smith, et al. Porosity in oxides on zirconium fuel cladding alloys, and its importance in controlling oxidation rates // Scr. Mater. 2010, v.62, p.564-567.

5. N. Ni, D. Hudson, J. Wei, P. Wang, S. Lozano-Perez, et al. How the crystallography and nanoscale chemistry of the metal-oxide interface develops during the aqueous oxidation of zirconium cladding alloys // Acta Mater. 2012, v.60, p.7132-7149.
6. A.T. Motta, M.J. Gomes Da Silva, A. Yilmazbayhan, R.J. Comstock, Z. Cai, B. Lai. Microstructural characterization of oxides formed on model Zr alloys using synchrotron radiation // 15-th International Symposium on Zirconium in the Nuclear Industry. ASTM STP, 2009, v.1505, p.486-506. West Conshohocken, PA: ASTM Int.

7. D.G. Kendall. The diffusion of shape // Advances in Applied Probability. 1977, v.9, N3, p.428-430.

8. C.-H. Lo, H.-S. Don. 3-D moments forms: their construction and application to object identification and positioning // IEEE Trans. Pattern Anal. Machine Intell. 1989, v.11, N10, p.1053-1064.

9. J.P. MacSleyne, J.P. Simmons, M. De Graef. On the use of moment invariants for the automated analysis of 3D particle shapes // Modelling and Simulation in Materials Science and Engineering. 2008, v.16, N4, p.045008.

10. A.I. Kul'ment'ev. Measurement of atomic clusters integral characteristics in computer simulation // Mathematical modeling. 2012, v.24, N3, p.97-112 (in Russian).

11. D.J. Wales, J.P.K. Doye, A.Dullweber, et al. The Cambridge cluster database // URL http://wwwwales.ch.cam.ac.uk/CCD.html.

12. N. Canterakis. 3D Zernike moments and Zernike affine invariants for 3D image analysis and recognition // 11th Scandinavian Conference on Image Analysis. 1999, p.85-93.

\section{МЕТОДЫ ОПИСАНИЯ ФОРМЫ ДЕФЕКТНЫХ НАНОСТРУКТУРНЫХ ОБРАЗОВАНИЙ В МАТЕРИАЛАХ ПОД ОБЛУЧЕНИЕМ}

\section{А. И. Кулъментъев}

В рамках программы использования современных компьютерных методов в задаче разработки радиационно стойких материалов для реакторов IV поколения рассмотрены несколько методов описания формы локальных атомных сегрегаций или компактных радиационных дефектов нанометрового диапазона. Предложен численный метод измерения формы произвольного атомного образования, обладающего хорошо определенной внешней границей. Выполнено измерение формы последовательности равновесных кластеров, взаимодействие частиц в которых описывается потенциалом Леннард-Джонса. В предложенном методе корректно воспроизводятся осцилляции размерных эффектов и последовательность магических чисел для этих кластеров. Рассмотрена возможность замены геометрических моментов на моменты $3 D$-функций Цернике. Такая замена позволяет избавиться от некорректного характера обратной задачи при переходе от исходного пространства форм в пространство их дескрипторов.

\section{МЕТОДИ ОПИСУ ФОРМИ ДЕФЕКТНИХ НАНОСТРУКТУРНИХ УТВОРЕНЬ У МАТЕРІАЛАХ ПІД ОПРОМІНЕННЯМ}

\section{О.І. Кульментъев}

У рамках програми використання сучасних комп'ютерних методів у завданні розробки радіаційно стійких матеріалів для реакторів IV покоління розглянуто кілька методів опису форми локальних атомних сегрегацій або компактних радіаційних дефектів нанометрового діапазону. Запропоновано чисельний метод вимірювання форми довільного атомного утворення, що має добре визначену зовнішню межу. Виконано вимір форми послідовності рівноважних кластерів, взаємодія частинок в яких описується потенщіалом Леннард-Джонса. У запропонованому методі коректно відтворюються осциляції розмірних ефектів та послідовність магічних чисел для цих кластерів. Розглянуто можливість заміни геометричних моментів на моменти $3 D$-функцій Цернике. Така заміна дозволяє позбутися від некоректного характеру оберненої задачі при переході від початкового простору форм у простір їх дескрипторів. 